\title{
PENGARUH PRAKTIKUM APLIKATIF BERBASIS CHEMOENTREPRENEURSHIP (CEP) TERHADAP HASIL BELAJAR SISWA DI KELAS XI MAS AMALIYAH SUNGGAL
}

\section{THE INFLUENCE OF CHEMOENTREPRENEURSHIP (CEP) APPLICATIVE PRACTICUM ON STUDENT LEARNING RESULTS IN CLASS XI MAS AMALIYAH SUNGGAL}

\author{
Dinda Nickyanti*, Julia Maulina, Dian Nirwana Harahap. \\ Universitas Islam Sumatera Utara, Department of Chemistry Education, Medan 20217, \\ North Sumatera, Indonesia \\ *Corresponding author : $\underline{\text { ikanickyanti0109@gmail.com }}$
}

\begin{abstract}
ABSTRAK
Penelitian ini bertujuan untuk mengetahui pengaruh praktikum aplikatif berbasis chemoentrepreneurship (CEP) terhadap hasil belajar siswa dan untuk mengetahui peningkatan hasil belajar pada materi koloid yang menggunakan metode praktikum aplikatif berbasis CEP dan metode ceramah. Penelitian ini dilakukan di X1 MAS Amaliyah Sunggal tahun ajaran 2018/2019 dengan menggunakan dua sampel kelas yaitu kelas kontrol yang menggunakan metode ceramah, dan kelas eksperimen menggunakan metode pembelajaran praktikum aplikatif CEP. Teknik pengumpulan data menggunakan lembar observasi dan tes. Hasil penelitian diperoleh rata - rata pretest siswa pada kelas eksperimen bernilai 37, sedangkan pada kelas kontrol 39. Pada postest rata - rata meningkat untuk kelas eksperimen bernilai 56 dan pada kelas kontrol memiliki rata - rata 52. Persentase pada kelas eksperimen yaitu 51,4\% sehingga termasuk kriteria sedang pada uji $\mathrm{N}$ - gain, sedangkan pada kelas kontrol tingkat persentase yaitu 33,3\% sehingga termasuk kriteria pada uji $\mathrm{N}$ - gain rendah. Berdasarkan hasil penelitian dapat disimpulkan bahwa terdapat pengaruh praktikum aplikatif berbasis CEP terhadap hasil belajar siswa materi koloid di kelas XI MAS Amaliyah Sunggal.
\end{abstract}

Kata kunci : chemoentrepreneurship , hasil belajar, koloid

\begin{abstract}
This study aims to investigate the influence of applied practical aplicatif chemoentrepreneurship (CEP) bases toward learning outcomes students and for influence improvement learning outcomes on colloid used practical methods CEP bases and talk methods. The research was conducted on the XI MAS Amaliyah Sunggal the school year 2018/2019 with use two sampling that is the control class using talk methods, and the experimental class using practical methods CEP bases. The techniq to collect the data using observation sheet and test. The result of this research obtained the average students class pretest of the class experiment the value 37, but of the control class the value 39. Postest the average improvment for the ecperiment class the value 56 and of the control class the
\end{abstract}


average 52. The persentase of the experiment class was 51,4\% was included on $N$ - gain test in the medium criteria, but the control class persentase level was 33,3\% was included on $N$ - gain test in the low criteria. Based on the result, it can be concluded that there are significant of practical of CEP applicative base toward learning outcome of students on colloid in class XI MAS Amaliyah Sunggal

Keywords : chemoentrepreneurship, colloid, learning outcomes

\section{PENDAHULUAN}

Ilmu kimia merupakan ilmu yang menuntut adanya pemahaman konsep serta penerapan konsep konsep dasar kimia tersebut dalam kehidupan sehari - hari. Sehingga hendaknya dalam proses pembelajaran didalam kelas dapat berlangsung secara menyenangkan. Namun fenomenanya sebagian kegiatan belajar hanya berlangsung melalui satu arah, yaitu guru ke siswa tanpa melibatkan siswa dalam memperoleh informasi. Sehingga siswa menjadi merasa bosan dan cenderung menggunakan teknik menghapal untuk mempelajari suatu materi pembelajaran, yang hanya bersifat sementara dan mempengaruhi hasil belajar siswa yang menjadi rendah.

Menurut Sudjana (2010), belajar bukan menghafal dan mengingat. Belajar adalah suatu proses yang ditandai dengan adanya perubahan pada diri seseorang. Pembelajaran dapat didefinisikan sebagai komunikasi yang dilakukan oleh guru dan siswa sebagai upaya guru untuk memberikan perubahan atau membentuk tingkah laku siswa. Tujuan pembelajaran adalah untuk membangun gagasan saintifik siswa (Hamdani, 2010). Proses pembelajaran akan berpengaruh terhadap hasil belajar (Nelia, 2014).

Belajar bukan hanya berupa penguasaan pengetahuan, tetapi juga kecakapan dan keterampilan dalam melihat, menganalisis, dan mengadakan pembagian kerja, serta kreativitas dalam menghasilkan suatu produk yang berkaitan dengan pembelajaran. Hal ini dapat dilihat dengan adanya suatu kegiatan praktikum sehingga dapat memudahkan penyampaian materi dengan cara hapalan, tetapi juga dalam menanamkan pemahaman yang mendalam kepada siswa.

Selama ini kegiatan praktikum yang sering dilakukan hanya seputar dunia laboratorium saja, tanpa adanya variasi dalam praktik untuk meningkatkan motivasi agar meningkatnya hasil belajar siswa. Dalam hal ini peneliti mencoba menerapkan praktikum yang berbasis chemoentrepreneurship (CEP) yang diharapkan dapat meningkatkan hasil belajar kimia siswa.

Konsep Chemoentreprenuership (CEP) adalah suatu konsep pembelajaran kimia untuk menumbuhkan semangat berwirausaha berbasis kimia. Pembelajaran dirancang dan dilaksanakan berangkat dari objek atau fenomena yang ada di lingkungan kehidupan, kemudian dikembangkan konsepkonsep kimia yang berkaitan dan proses kimia yang melandasi, termasuk faktor-faktor yang mempengaruhi proses tersebut hingga sampai pada kesimpulan yang bermakna. Inti dari pendekatan $C E P$ bukan membentuk siswa menjadi seorang wirusahawan atau pedagang, tetapi pembelajaran dengan pendekatan $C E P$ diharapkan akan menumbuhkan semangat/jiwa kewirausahaan bagi siswa dalam proses belajar mengajar. Semangat/jiwa kewirausahaan seseorang tercermin pada berbagai hal misalnya kemampuan, kemandirian termasuk di dalamnya adalah kegigihan, kerjasama dalam tim, kreativitas dan inovasi. (Roni, 2015)

Dalam mata pelajaran kimia terdapat beberapa materi pokok, salah satunya yaitu materi koloid. Materi ini sangat erat dengan kehidupan sehari - hari. Namun pada kenyataannya materi koloid ini dirasa siswa kurang bermakna dalam kehidupan. Hal ini dipandang dikarenakan kurangnya penjelasan guru mengenai manfaat dan penerapannya. Karakteristik matei koloid juga terdiri dari konsep dan pemahaman yang cukup rumit, misalnya dalam langkah - langkah pembuatan koloid, sifat maupun jenis - jenis koloid. Maka dari itu penulis ingin melihat hasil belajar siswa melalui praktikum yang berbasis chemoentrepreneurship (CEP). 
Adapun tujuan dari penelitian ini adalah : 1. Untuk mengetahui pengaruh praktikum aplikatif berbasis CEP pada selai tomat terhadap hasil belajar siswa pada materi koloid. 2. Untuk mengetahui peningkatan hasil belajar siswa yang diajarkan dengan menggunakan metode praktikum aplikatif berbasis CEP pada pembuatan selai tomat.

\section{METODE PENELITIAN}

Penelitian ini dilaksanakan di MAS Amaliyah Sunggal Kelas XI IPA 1 dan XI IPA 2 tahun pembelajaran 2018/2019 pada bulan Maret - Juli semester Genap tahun 2019. Jenis penelitian ini merupakan penelitian kuantitatif dengan menggunakan desain Pretest - Postets Control Group Design yaitu desain eksperimen dengan melihat perbedaan antara pretes dengan postes antara kelas eksperimen dengan kelas kontrol. Dalam penelitian ini digunakan instrumen berupa lembar observasi dan tes untuk memperoleh data yang dibutuhkan. Instrumen ditujukan untuk mengetahui pengaruh praktikum aplikatif berbasis chemoentrepreneurship (CEP) serta untuk mengetahui respon siswa terhadap praktikum aplikatif berbasis chemoentrepreneurship (CEP) dan peningkatan hasil belajar. Uji statistik dilakukan pada taraf signifikansi 5\%. Uji hipotesis yang digunakan dalam penelitian ini menggunakan uji normalitas, uji homogenitas, uji hipotesis Data, uji N - Gain.

\section{HASIL DAN PEMBAHASAN}

\subsection{Hasil Penelitian}

Penelitian ini dilaksanakan di MAS Amaliyah Sunggal kelas XI IPA 1 sebagai kelas kontrol dan kelas XI IPA 2 sebagai kelas eksperimen. Penelitian ini menggunakan dua sampel kelas yaitu kelas kontrol menggunakan metode pembelajaran ceramah dan kelas eksperimen menggunakan metode praktikum aplikatif berbasis chemoentrepreneurship (CEP). Metode pembelajaran praktikum aplikatif berbasis CEP merupakan pemebelajaran kimia yang menggunakan metode praktikum yang dikaitkan dengan objek nyata sehari - hari. Pengaplikasian praktikum CEP ini menyebabkan siswa dapat mengolah suatu bahan sederhana menjadi sebuah produk yang bermanfaat dan bernilai ekonomis. Produk yang dihasilkan merupakan selai berbahan dasar buah tomat.

Analisis data dilakukan untuk menjawab hipotesis yang telah diajukan. Data yang digunakan yaitu data dari nilai pretes dan postes. Analisis data ini meliputi uji normalitas, uji homogenitas, uji hipotesis dan uji N-Gain.

\section{a. Uji Normalitas}

Uji normalitas ini bertujuan untuk melihat apakah kedua kelompok terdistribusi secara normal atau tidak. Pengujian ini menggunakan uji Liliefors dengan bantuan Micrososft Excel 2007 dengan taraf signifikan $\alpha=5 \%$ dengan $\mathrm{n}_{1}=29$ dan $\mathrm{n}_{2}=31$ sehingga diperoleh $\mathrm{L}_{\text {tabel }} 0,161$ dan 0,156 dengan kriteria jika harga $\mathrm{L}_{\text {hitung }}>\mathrm{L}_{\text {tabel }}$ maka data tersebut berdistribusi normal. Berikut dibawah ini tabel data hasil belajar siswa dari hasil pretes dan postes siswa.

Tabel 1. Uji Normalitas Masing - Masing Kelompok

\begin{tabular}{|c|c|c|c|c|c|}
\hline & \multicolumn{3}{|c|}{ Eksperimen } & \multirow{2}{*}{$\begin{array}{l}\text { Kontrol } \\
\mathrm{L}_{\text {tabel }} \\
\end{array}$} & \multirow{2}{*}{ Distribusi } \\
\hline & $\mathrm{L}_{\text {hitung }}$ & $\mathrm{L}_{\text {tabel }}$ & $\mathrm{L}_{\text {hitung }}$ & & \\
\hline Pretes & 0,205 & \multirow{2}{*}{0,161} & 0,785 & \multirow{2}{*}{0,156} & NORMAL \\
\hline Postes & 0,167 & & 0,172 & & NORMAL \\
\hline
\end{tabular}


Dari hasi analisis seperti yang ditampilkan diatas pada kelas eksperimen nilai pretes 0,205 dan postes 0,167 memiliki nilai yang lebih besar dibandingkan dengan $\mathrm{L}_{\text {tabel }}$ sebesar 0,161 . Sedangkan pada kelas kontrol untuk pretes 0,785 dan postes 0,172 lebih besar dibandingkan dengan $\mathrm{L}_{\text {tabel }}$ sebesar 0,156 sehingga untuk kelas eksperimen dan kelas kontrol dalam penelitian ini dapat disimpulkan bahwa kedua sampel tersebut berdistribusi normal.

\section{b. Uji Homogenitas}

Pada uji homogenitas ini digunakan untuk melihat apakah antara kedua kelas memiliki varians yang sama dengan taraf signifikan $\alpha=0,05$ dengan kriteria jika $\mathrm{F}_{\text {Hitung }}<\mathrm{F}_{\text {Tabel }}$ maka kedua varians memiliki kesamaan. Hasil pengujian data pretes dan postes siswa terangkum dalam tabel dibawah ini.

Tabel 2. Uji Homogenitas Dua Varians

\begin{tabular}{cllllll}
\hline \multirow{2}{*}{$\mathrm{S}^{2}$} & \multicolumn{2}{c}{ Kelas } & & $\mathrm{F}_{\text {hitung }}$ & $\mathrm{F}_{\text {tabel }}$ & Kesimpulan \\
\cline { 2 - 3 } & Eksperimen & Kontrol & & & & \\
\hline Pretes & 1115,716 & 1249,649 & 0,893 & 1,854 & Homogen \\
\hline Postes & 1650,18 & 1583,82 & 1,0419 & 1,854 & Homogen \\
\hline
\end{tabular}

Dari data tabel di atas bahwa $\mathrm{F}_{\text {hitung }}$ pada pretes berjumlah 0,893 dan $\mathrm{F}_{\text {hitung }}$ pada postes berjumlah 1,0419 untuk nilai $F_{\text {tabel }}$ berjumlah 1,854. Sehingga di peroleh $\mathbf{F}_{\text {hitung }}<\mathbf{F}_{\text {tabel }}$ maka dapat disimpulkan bahwa data dari kedua sampel Homogen.

\section{c. Uji Hipotesis Data}

Pengujian ini dilakukan untuk melihat perbedaan hasil belajar dari kedua sampel dengan taraf signifikan $\alpha=0,05$. Untuk melihat hasl uji ini dapat dilihat dari tabel dibawah ini.

Tabel 3. Uji Hipotesis

\begin{tabular}{|c|c|c|c|}
\hline & $\mathrm{T}_{\text {hitung }}$ & $\mathrm{T}_{\text {tabel }}$ & Kesimpulan \\
\hline Pretes & 4,520 & \multirow{2}{*}{2,048} & \multirow{2}{*}{$\begin{array}{l}\mathrm{H}_{\mathrm{a}}=\text { diterima } \\
\mathrm{H}_{0}=\text { ditolak }\end{array}$} \\
\hline Postes & 5,278 & & \\
\hline
\end{tabular}

Dari hasil uji hipotesis diatas dapat disimpulkan $\mathrm{T}_{\text {hitung }}>\mathrm{T}_{\text {tabel }}$ dengan nilai $\mathrm{T}_{\text {hitung }}=5,278$ dan $\mathrm{T}_{\text {tabel }}$ $=2,048$, hal ini berarti bahwa Ha diterima sehingga dapat disimpulkan bahwa "ada pengaruh yang signifikan terhadap hasil belajar siswa yang diajar dengan menggunakan metode praktikum aplikatif berbasis CEP”.

\section{d. Uji N - Gain}

Uji $\mathrm{N}$ - gain dilakukan untuk melihat peningkatan nilai pretest ke postest dengan rumus sebagai berikut : 


$$
N-\text { Gain }=\frac{\text { postets }- \text { pretest }}{100-\text { pretest }}
$$

Kriteria keberhasilan dalam uji $\mathrm{N}$ - Gain dapat ditentukan dengan indikator sebagai berikut : $\mathrm{N}-$ gain $<0,3=$ rendah

$$
\begin{array}{ll}
0,3<\mathrm{N} \text {-gain }>0,7 & =\text { sedang } \\
\mathrm{N} \text {-gain }>0,7 & =\text { tinggi }
\end{array}
$$

Tabel 4. Rata - Rata Nilai Siswa

\begin{tabular}{lll}
\hline Rata - Rata & Eksperimen & Kontrol \\
\hline Pretes & 37 & 39 \\
\hline Postes & 56 & 52 \\
\hline
\end{tabular}

$N-$ Gain $=\frac{\text { postets }- \text { pretest }}{100-\text { pretest }}=\frac{56-37}{100-37}=\frac{19}{63}=0,3$

$\%$ Peningkatan $=\frac{56-37}{37} \times 100 \%=51,4 \%$

Berdasarkan perhitungan diatas, diperoleh data hasil belajar siswa pada kelas eksperimen memiliki keberhasilan yang Sedang dikarenakan hanya memiliki indeks nilai sebesar 0,3. Sedangkan pada persentasenya hanya memiliki peningkatan sebesar 51,4\%.

Sedangkan pada kelas kontrol, berikut perhitungannya :

$N-$ Gain $=\frac{\text { postets }- \text { pretest }}{100-\text { pretest }}=\frac{52-39}{100-39}=\frac{13}{61}=0,21$

$\%$ Peningkatan $=\frac{52-39}{39} \times 100 \%=33,3 \%$

Pada kelas kontrol peningkatan hanya sebesar 33,3\% dengan indeks gain nya sebesar 0,21 sesuai dengan kriteria indeks gain, kelas kontrol memiliki kriteria yang Rendah.

\subsection{Pembahasan}

Penelitian pada kelas eksperimen menggunakan pembelajaran dengan metode praktikum aplikatif berbasis CEP sedangkan pada kelas kontrol menggunakan metode ceramah. Pembelajaran pada kedua sampel dilakukan dengan memberikan pretes kepada siswa untuk melihat kemampuan awal siswa mengenai jenis - jenis koloid. Setelah itu kedua sampel tersebut dibagi menjadi beberapa kelompok. Postes pada kelas eksperimen dan kelas kontrol dilaksanakan setelah proses pembelajaran selesai untuk memperoleh hasil belajar siswa.

Berdasarkan observasi yang dilakukan selama pembelajaran pada kelas kontrol dan kelas eksperimen menunjukkan respon yang berbeda. Dimana pada kelas eksperimen yang melakukan praktikum aplikatif berbasis CEP, siswa lebih aktif serta lebih giat dalam kegiatan belajar mengajar $(\mathrm{KBM})$. Hal ini dikarenakan pembelajaran lebih menyenangkan, dibandingkan dengan metode pembelajaran ceramah pada kelas kontrol dimana hanya beberapa siswa saja yang aktif memberikan pertanyaan, selebihnya siswa cenderung pasif dalam pembelajaran hal ini disebabkan karena kegiatan belajar mengajar lebih dominan pada guru sehingga pembelajaran membosankan dan siswa merasa jenuh. 
Sesuai dengan hasil data perhitungan yang telah dilakukan bahwa setiap kelas berdistribusi normal diketahui dari jumlah $\mathrm{L}_{\text {hitung }}$ lebih besar dari $\mathrm{L}_{\text {tabel }}$ atau $\mathrm{L}_{\text {hitung }}>\mathrm{L}_{\text {tabel }}$. Pada kelas eksperimen bernilai 0,205 $>0,161$ sedangkan pada kelas kontrol bernilai 0,785 > 0,156. Selain bernilai normal, kedua kelas juga berdistribusi homogen dikarenakan $F_{\text {hitung }}$ lebih kecil dari $F_{\text {tabel }}$ atau $F_{\text {hitung }}<F_{\text {tabel, }}$ dengan nilai 0,893< 1,854 untuk pretes, sedangkan pada postesnya yaitu 1,045 $<1,854$. Berdasarkan hal tersebut sehingga dapat dicari nilai dari hasil belajar siswa melalui uji test. Dengan distribusi $\mathrm{T}_{\text {hitung }}>\mathrm{T}_{\text {tabel }}$ yaitu $\mathrm{T}_{\text {hitung }}$ bernilai 5,274 dan $\mathrm{T}_{\text {tabel }}$ 2,048 atau 5,274 > 2,048. Sehingga hasil hipotesis $\mathrm{H}_{\mathrm{a}}$ diterima dan $\mathrm{H}_{0}$ ditolak.

Berdasarkan data dan hasil perhitungan yang telah diperoleh dalam penelitian ini, pada kelas eksperimen yang menggunakan metode praktikum aplikatif CEP memiliki peningkatan belajar sebesar $51,4 \%$, sedangkan pada kelas kontrol peningkatan hasil belajar yang dilakukan dengan metode ceramah hanya sebesar $33,3 \%$.

\section{SIMPULAN DAN SARAN}

\section{1 Simpulan}

Berdasarkan hasil penelitian dan pembahasan maka dapat ditarik kesimpulan sebagai berikut:

1. Ada pengaruh yang signifikan terhadap hasil belajar siswa dengan menggunakan metode praktikum aplikatif berbasis chemoentrepreneurship (CEP) dengan nilai $\mathrm{T}_{\text {hitung }}$ pada postes $=5,278$ dengan $\mathrm{T}_{\text {tabel }}$ $=2,048$, sehingga dapat dibandingkan $\mathrm{T}_{\text {hitung }}>\mathrm{T}_{\text {tabel }}$ bearti $\mathrm{H}_{0}$ ditolak dan $\mathrm{H}_{\mathrm{a}}$ diterima.

2. Berdasarkan $\mathbf{N}$ - Gain menunjukkan hasil belajar siswa pada kelas eksperimen meningkat sebesar $51,4 \%$.

\section{2 Saran}

Berdasarkan hasil penelitian, peneliiti menyarankan :

1. Penggunaan pembelajaran praktikum aplikatif berbasis CEP tidak memberikan hasil belajar yang signifikan. Oleh karena itu perlu dilakukan modivikasi dengan model pembelajaran lainnya sehingga meningkatkan hasil belajar yang signifikan.

2. Metode praktikum berbasis CEP pada bidang studi kimia dapat dijadikan sebagai variasi metode pembelajaran untuk upaya peningkatan hasil belajar siswa

3. Perlu dilakukan penelitian lanjutan untuk materi pokok yang berbeda.

\section{DAFTAR PUSTAKA}

Hamdani. 2010. Strategi Belajar Mengajar. Bandung : Pustaka Setia

Nelia, Adora M.2014. Group Investigasi In Teaching Elementary Science. International Journal Of Humanities And Management Science. Vol 2. Issue 3, ISSN 2320-40444

Roni, Ropinus, dkk. 2015. Upaya Meningkatkan Hasil Belajar Siswa Menggunakan Metode Praktikum Dengan Pendekatan Chemoentrepreneurship Materi Sistem Koloid: Program Studi Pendidikan Kimia FKIP UNTAN

Sudjana, Nana. 2010. Penilaian Hasil Proses Belajar Mengajar. Bandung: PT. Remaja Rosdakarya 